\title{
FISSURA ANAL
}

\author{
DR. PAULO P. VAMPRE
}

\section{DEFINIÇÃO}

FISSURA ANAL é uma pequena ulceração superficial e alongada do revestimento do canal anal, situada quasi sempre na comissura posterior do anus, manifestando-se clinicamente por dores, atrózes por vezes, durante e depois do ato da defecação e por-contratura espasmódica do esfíncter externo do anus.

\section{INCIDENCIA E LOCALISAÇÃO}

E' encontrada frequentemente nas clinicas ano-retaes; na clinica especialisada da Mayo Clinic, em dez anos entrou na percentagem "de nove por cento.

Quasi sempre única e na comissura posterior do anus; Levy (10) em 124 casos, 115 eram da comissura posterior; Pruitt (17) encontrou na comissura posterior $99 \%$ e $92 \%$ respectivamente no homem e na mulher; nos casos de Bacon, (1) $10,8 \%$ eram da comissura anterior, 88,1 da posterior e 1,1\% fissuras laterais do anus.

\section{ETIOPATOGENIA}

Para Lochart-Mummery (11) e a maioria dos autores a fissura anal seria devida a divergencia em $Y$ de certas fibras do esfíncter externo que do cóccix dirige-se para a frente pelos lados do anus. Esta disposição anatomica não explicaria porque a fissura não existe acima do septo intermuscular do anus, nas zonas onde se dá a divergencia em $Y$ de taes fibras, mas ocorre mais caudalmente, na porção subcutânea do esfincter, nas fibras que não se inserem no cóccix, fibras que são circulares ao anus.

Não sendo satisfatória a hipótese da divergencia $Y$ das fibras do esfíncter, procurou Blaisdell (4) explicar a patogenia e

(*) Preleção realizada no dia 10 de junho de 1940 em reunião interna do Departamento de Tecnica Cirúrgica e Cirurgia Experimental da Faculdade de Medicina da Univer sidade de São Paulo. 
nos deu inteira satisfação; para entendel-a é necessario que se recorde a musculatura do canal anal, tão bem descrita por Miligan e Morgan (13).

Músculos do canal anal: (Fig. I e II) - Esfíncter externo do anus - E um musculo trilamelar que com a porção puboretal do elevador do anus, forma um forte cilindro muscular que envolve longitudinalmente o esfíncter interno do anus e o canal anal. E formado por três camadas de fibras (por vezes apenas duas, sendo inseparaveis as duas profundas): esfíncter externo subcutâneo, superficial e profundo. Os esfíncteres externos subcutâneo e profundo são músculos anulares que não se inserem no cóccix, inervados pelo nervo hemorroidal inferior e $3 .^{\circ}$ e $4 .^{\circ}$ sagrados; o esfíncter externo superficial é eliptico, insere-se no coccix e inervado pelo $4 .^{\circ}$ sagrado.

Um septo fibro muscular, prolongamento longitudinal dó reto encontra-se entre as tres porções. A primeira porção, o esfincter externo subcutâneo, está situado abaixo, em um mesmo plano que o esfincter interno e está em relação direta com o canal anal; nada ha interposto entre êle e a mucosa do anus. A segunda e terceira porções (e. ext. superficial e profundo) envolvem o músculo longitudinal e o esfíncter interno do anus. O esfíncter externo subcutâneo é separado do esfíncter interno por uma bandeleta anular, uma fáscia, o septo anal intermuscular.

O esfíncter externo superficial insere-se posteriormente no cóccix e dirigindo-se para a frente, suas fibras divergem em $\mathrm{Y}$, passando pelos lados do canal anal acima da porção subcutânea e abaixo da porção profunda, e unem-se adeante do canal anal do ponto central do períneo.

O esfíncter externo profundo tem relações íntimas com as fibras pubo retaes do elevador do anus na sua metade posterior, onde sua borda superior é mal definida; sua borda inferior é separada do esfíncter externo superficial por um septo fibroso por vezes não bem definido. E, das porções do esfíncter externo, a menos individualisada.

Elevador do anus: (Fig. I) - Este músculo pode ser dividido em ileococigeo, que da espinha isquiática e da parte posterior da linha branca se insere no cóccix e no rafé anococcigeal ; sem conexão com o reto e o canal anal; pubococigeo, com fibras que vêm de pubis e das porções anteriores da fascia obturadora e dirigem-se para tras, horizontalmente pelos lados do reto, acima do puboretal, fibras que se unem atrás do reto em um rafe denso; finalmente o puboretal de grande importancia na função retal, vem do pubis e do ligamento triangular, dirige-se para trás e para baixo, pelos lados do reto e 


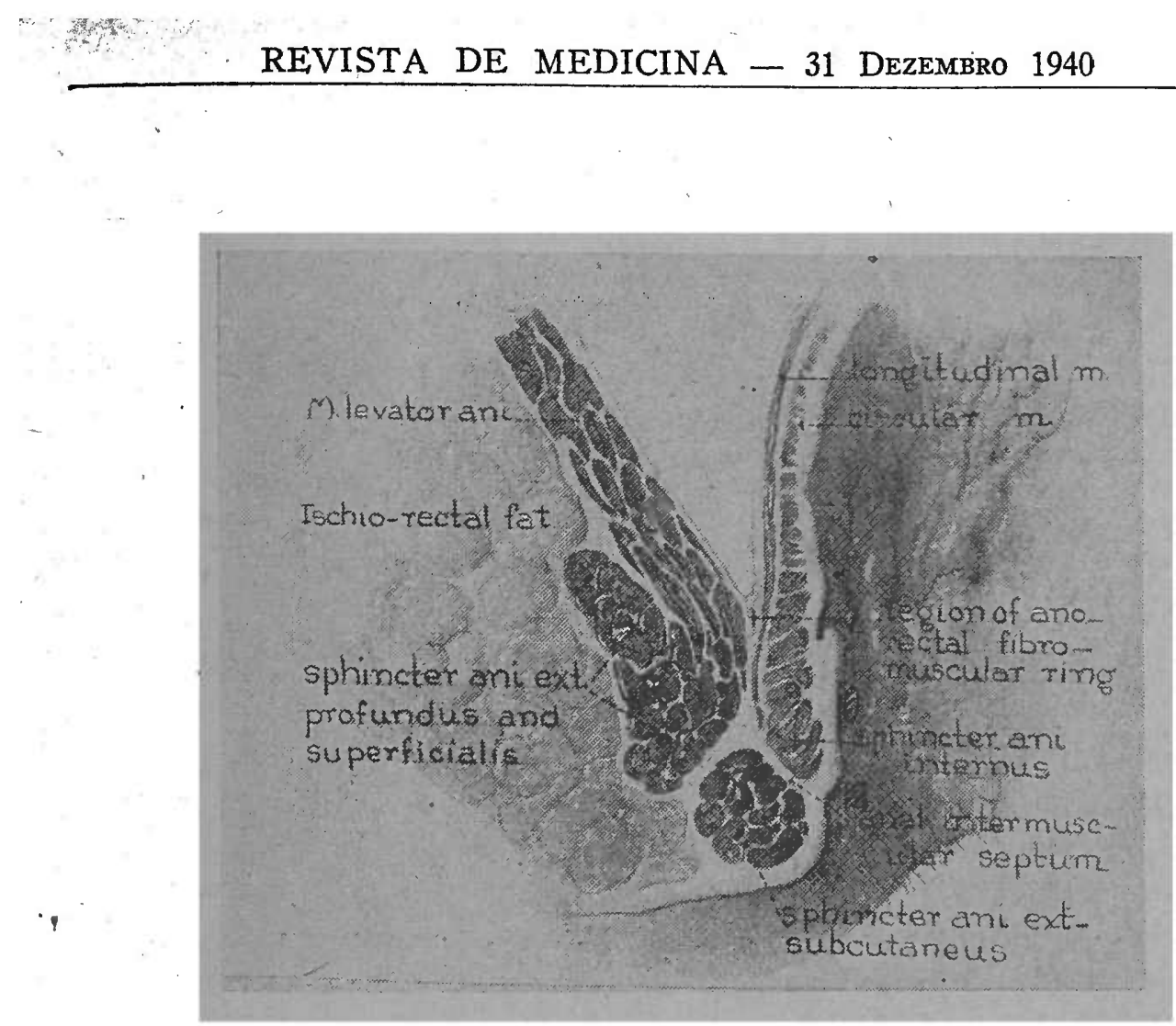

FIG. I

(Miligan e Morgan (13)

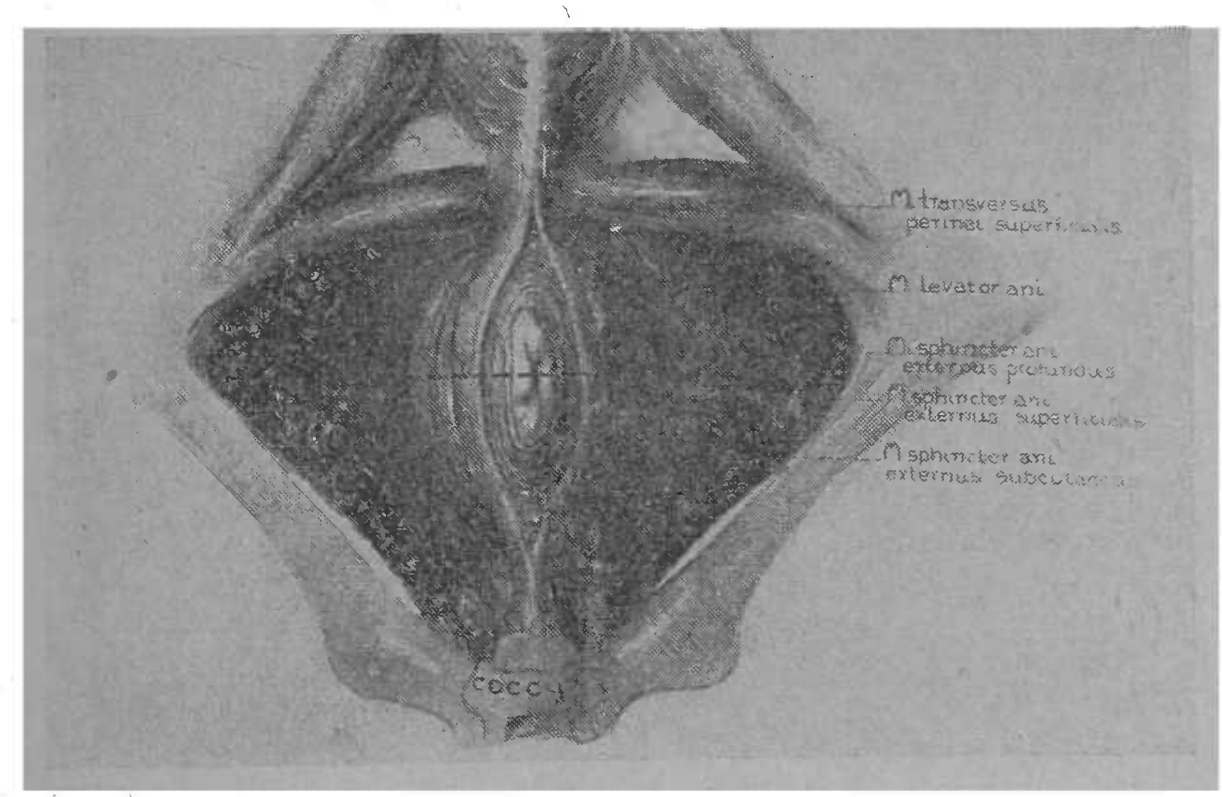

FIg. II

(Miligan e Morgan (13) 
encontra-se com o do lado oposto atrás do canal anal, formando uma poderosa cinta, que puxa e atrae a junção ano-retal ao pubis. Suas fibras não chegam ao cóccix. E' o músculo melhor desenvolvido do diafragma pélvico, tem relações por vezes íntimas com o esfíncter externo do anus. Abaixo dele está o canal anal e entre os dois, os músculos longitudinaes do reto. O elevador é inervado pelo $4 .^{\circ}$ sagrad oe ramos do pudendo interno.

Músculo longitudinal do canal anal - E' o prolongamento da camada muscular do reto, que envolve o canal anal. Na extremidade superior do canal anal torna-se fibro muscular, confunde-se na metade posterior com o puboretal que fica por fóra e tambem com o esfíncter externo profundo na sua metade anterior, onde o puboretal deixa o canal anal. Entra na formação do anel ano-retal; termina dividindo-se em três septos fibro musculares que separam as varias porções do esfíncter externo. O septo que continua o musculo caudalmente, passa entre o esfincter interno e a porção subcutânea do esfíncter externo, formando o septo intermuscular no anus, que chega até a junção cutâneo-mucosa do anus.

Esfíncter interno do anus: (Fig. I) - E' um músculo tubular cilindrico que envolve o canal em sua quasi totalidade; termina em plano acima do esfíncter externo subcutâneo; é a continuação direta das fibrás musculares circulares da parede do reto.

Conhecida assim a musculatura do canal anal, vejamos, para explicar a patogenia da fissura anal, como êle se comporta à passagem das fezes no ato da defecação.

A parede intestinal, com esfíncter interno e porção profunda de esfíncter externo é bem forte e auxiliada ainda pelo elevador do anus. Mais abaixo é bem constituida pela porção superficial do esfíncter externo. A porção subcutânea no esfíncter externo, a menor de todas, não é reforçada por outro elemento, não tem ligações com cóccix, forma uma barreira que impede a progressão das fezes. Como é fraca, distende-se e distendendo-se em excesso, rompe-se a camada de revestimento do canal anal sub jacente e instala-se a fissura.

Vejamos para maior clareza os esquemas muito eludicativos de Blaisdell (4) (Figs. 3, 4 e 5). 


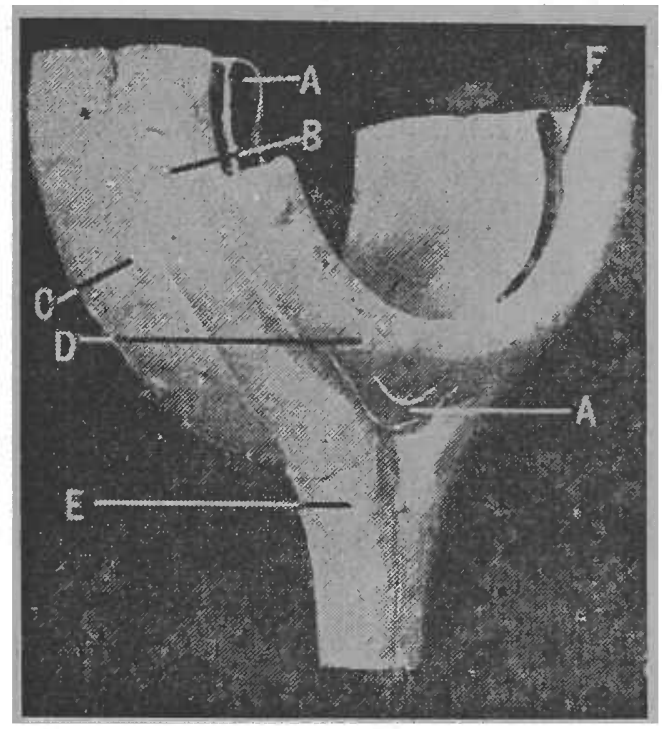

FIG.' III

Modelo dos musculos esfincterianos do anus, secção feita sobre a linha pontilhada da fig. II. Não está incluido o elevador do anus. Músculos representados dilatados. $A$, borda inferior do esfincter interno, sendo que uma pequena porção do esfíncter externo subcutaneo foi cortada no alto, a esquerda, mostrando que essa porção $e$ o esfíncter interno acham-se em um mesmo plano. $B$, porção superficial do esfíncter externo, com fibras divergentes $E$ que se incerem no cóccix. $C$, porção profunda do esfíncter externo, composto só de fibras circulares. $D$, porção subcutânea do mesmo esfíncter, só dé fibras circulares, que não envolvem e não suportam o esfíncter interno, como as porçỗes superficiais e profundas, mas em um mesmo plano do qué êle e separado pelo septo intermuscular $F$.

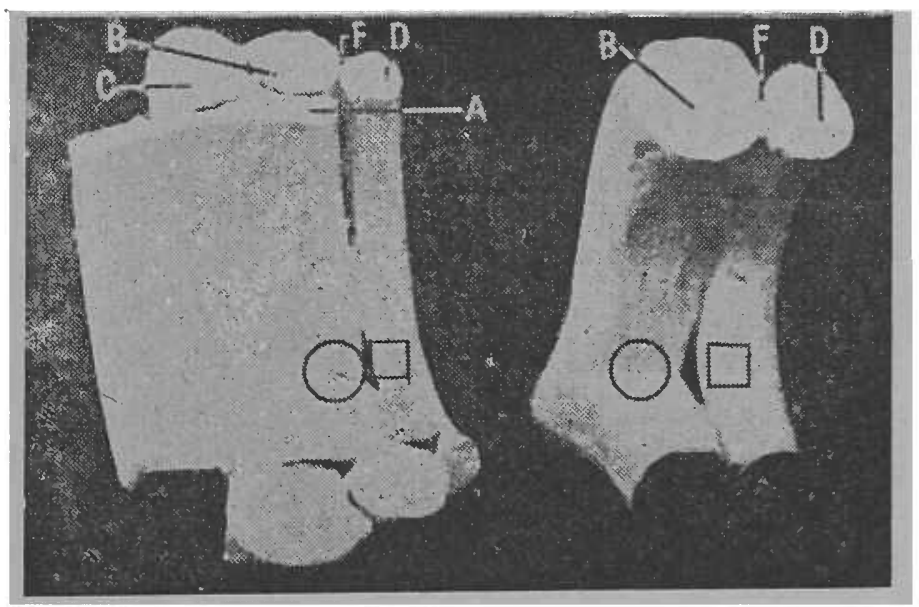

FIG. IV

A esquerda, o modelo da fig. visto de cima para baixo; a direita segmentos das porções subcutânea $\epsilon$ superficial do esf. externo, mostrando as fibras divergentes do último. Si essas fibras divergentes fossem a causa da fissura estas deveriam estar situadas no local do circulo (na mesma posição em todos os modelos); mas as fissuras circulo (na mesma posiçáo em todos os mo local assinalado pelo quadrado. As nunca ai se localisam, e sim no local assinalado pelo quadrado.
letras representam as mesmas estruturas da figura anterior. 


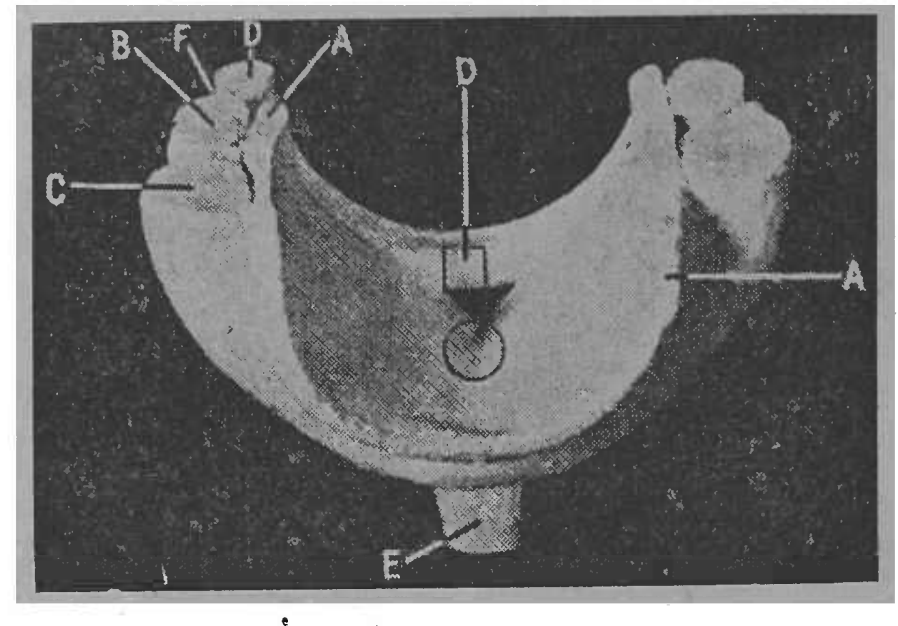

FIG. V

Mesmo modelo da fig. III, visto agora de dentro do canal anal para fora, com os músculos dilatados. A formação de uma barreira posterior (e menos acentuadamente uma barreira anterior) pela, comparativamente fraca e sem suporte, porção subcutânea do esfíncter externo (D) que se opõe e dificulta a progressāo das fezes está nitidamente demonstrada. $E$ ' esta porção do esfíncter externo, que' estirada pela progressāo do bolo fecal, provoca a ruptura da mucosa e a instalação da fissura anal. Causa evidentemente anatômica, explica porque as fissuras do anus se localisam quasi que exclusivamente na comissura posterior e abaixo do septo intermuscular, mais distalmente do que o esfíncter interno.

Devemos entretanto lembrar a hipótese de Buie, (5) que condiciona a maior percentagem de fissuras na comissura posterior pela relação dos eixos do canal anal e o do reto; formam os dois um ángulo aberto para tras que aliada da curvatura do reto que acompanha a do sacro, faz com que o maior pressão no momento da defecação se faça na parede posterior. Ainda quanto a etiopatologia devemos salientar a importancia da prisão de ventre; individuos constiados crônicos com fezes secas e endurecidas, são naturalmente mais propensos a instalação de uma fissura, sabendo-se que a causa eficiente é o trauma pela passagem das fezes pela porção subcutânea do esfíncter externo.

\section{SINTOMATOLOGIA}

Apresenta-se a fissura anal como uma ulceração superficial, de fundo claro, mole, elástica, ulceração que é mantida pela contração do esfíncter e pela irritação constante com a defecação. As bordas da ulceração com o tempo tornam-se endurecidas, congestas. Apresentam em sua comissura inferior uma porção de pele edematosa, a chamada hemorroida sentinela, de origem não hemorroidária, representando o edema da pele pelo bloqueio das veias superficiais.

O sintoma principal é a dor; dor paraxística, de queimação, por vezes atrozes e insuportáveis. Iniciam-se no momento da defecação e prolongam-se por tres, quatro horas; localisam-se no anus, acompa- 
nham-se de espasmo do esfíncter que mantem afastadas as bordas da fissura o que provoca a dor.

A dor é caracterisada por apresentar um espaço livre, logo após a dor pela defecação, e por se intensificar momentos depois pela contração espasmódica do esfíncter externo; esta segundo fase é mais intensa e mais duradoura e a mais insuportavel e desesperante. O ciclo doloroso tipico de fissura do anus pode ser representada pelo grafico abaixo (Bacon):

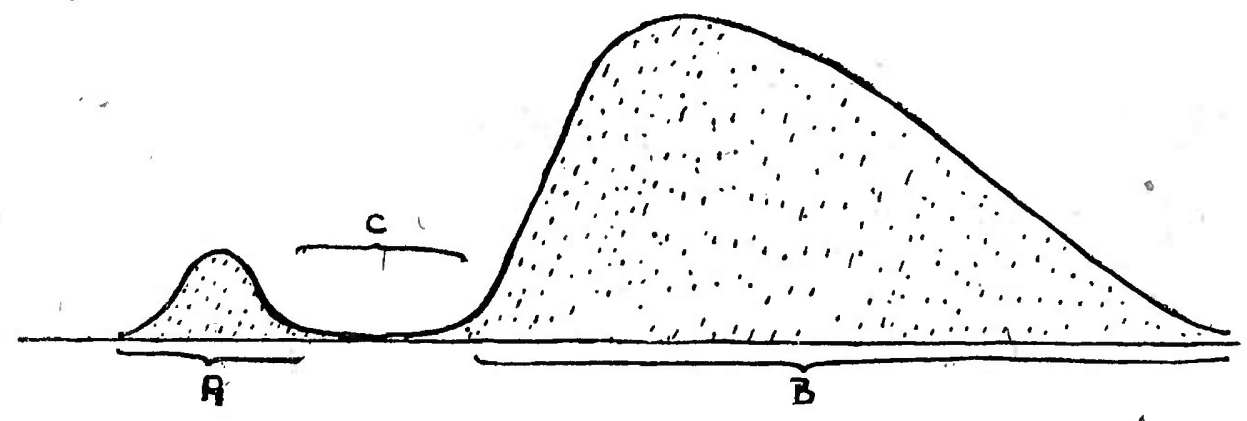

(A Dor no ato da defecação. - B) Dor por contração espasmodica do esfinter. - C) intervalo livre de dor.

Outros sintomas da fissura são o sangramento pequeno pela defecação; constipação, causa e sequela da fissura; sintomas reflexos em virtude das relações anatomicas entre os nervos do canal anal com os dos orgãos genito-urinarios.

\section{TRATAMENTO}

Conhécida a etiopatogenia da fissura, temos o seu tratamento: suprimir a barreira do esfíncter externo subcutâneo.

$\mathrm{Ha}$ entretanto outros metodos - o paliativo, onde os cuidados locaes com pomadas de ictiol, collargol associado a belladona, toques com nitrato de prata a $1 \%$, etc. se aliam aos cuidados gerais que visam via de regra impedir a constipação por meio de uso constante de laxativos, o que diminuia o trauma causado pelas fezes duras e resequidas.

Ha ainda e em grande número os partidarios do tratamento esclerosante ou com oleos anestésicos. Varios são os agentes empregados. A solução de quinina e uréa a $5 \%$, preconisada por Graham, dá em suas mãos mais. de $80 \%$ de curas; de técnica simples podemos resumir em algumas palavras: - posição de talha ou genupeitoral; desinfecção dọ campo operatorio; anestesia local por tampões de novocaina a $5 \%$ e depois com agulha de bisel curto, injecta-se 1/10 a 1/4 de cc., imediatamente acima da extremidade superior da fissura. A agulha deve penetrar 4 a 5 mil. paralelamente a superficie da lesão, na sub'mucosa, ao mesmo tempo que se injecta rapidamente o liquido; dóe bastante, dôr de curta duração, que se substitue por 
analgesia e bem estar. Uma injecção por vezes é o suficiente, necessitando outras vezes tres ou quatro. Para acelerar a cicatrisação pomada de ictiol ou balsamo de Perú. A cicatrisação se dá de 6 a 14 dias.

Bensaude (3) em 149 doentes empregou sempre com bons resultados a técnica que se segue - depois de desinfecção do campo e anestesia local por tampões de novocaina a $5 \%$ faz a infiltração do esfíncter lateralmente a fissura, assim como da base da mesma; injectando solução de novocaina a $1 / 200$ com agulha penetrando a $2 \mathrm{cms}$. do anus no sulco-coccigeano, depois de 2 a 3 minutos injecta o oleo anestesiante que preconisa, formula de Lacharte

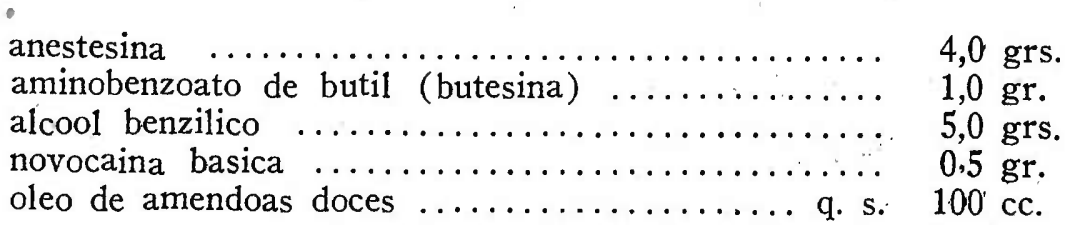

Injecta 5 a $10 \mathrm{cc}$. dessa solução em varios pontos, injecção em leque, com o cuidado de não perfurar a mucosa. Depois massagem do * anus.

I Gabriel (7) aconselha e prefere um dos dois oleos anestesiantes.
A) Anestesina $\ldots \ldots \ldots, 3 \%$
Alcool benzilico ...... $5 \%$
Ether $\ldots \ldots \ldots \ldots \ldots, 10 \%$
B) $\begin{aligned} & \text { Percaina } \ldots \ldots \ldots \ldots \\ & \text { Fenol } \ldots \ldots \ldots \ldots \ldots\end{aligned}$

Injecta de cada lado da fissura $2,5 \mathrm{cc}$. de uma ampoula de $5^{\circ} \mathrm{cc}$. de uma das soluções que preconisa, previamente aquecida a temperatura do corpo; ha no momento dor de queimação local que dura 3-4 horas e que desaparece substituida por grande sensação de bem estar. Tem muto bons resultados mas acha que como toda injecção esclerosante ou por meio dos oleos anestesicos só tem aplicação nas fissuras recentes.

Finalmente temos o tratamento cirurgico, que pode ser dividido em tres metodos: - o da divulção, o da incisão e o da excisão da fissura.

Visam os tres suprimir a causa; a barreira do esfíncter externo subcutâneo, ou seja a barreira da porção subcutânea do esfíncter externo.

A divulção, manobra facil mas cuja técnica deve ser como mostra a figura VI na sequencia de $a$ para $e$, dispensa maiores comentários; esta manobra é tambem o tempo inicial dos processos de excisão e de incisão.

A incisão como seu nome indica, incisa a fissura; a incisão se inicia na extremidade superior, desce por sua parte media até $1 / 2 \mathrm{cms}$. 


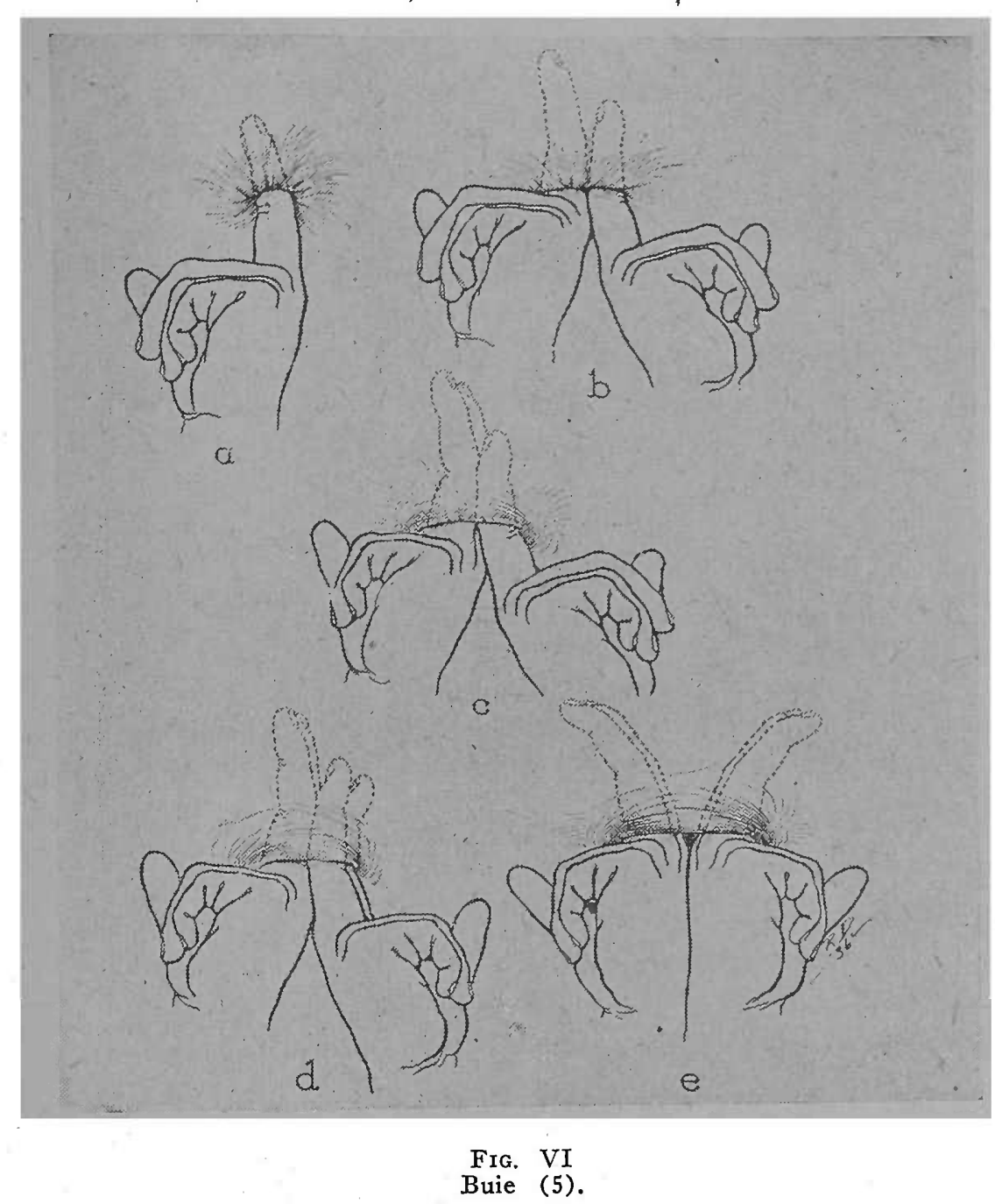

abaixo de sua extremidade inferior; incisão pouco profunda que secciona a fissura, as fibras mais superficiais do esfíncter externo.

E feita sob a anestesia local, a mesma que se usa para excisão. Depois de desinfecção do campo operatório, faz-se um botão dérmico a $1 \mathrm{~cm}$. abaixo da borda posterior da fissura e injecta-se $1 \mathrm{cc}$. da solução de novocaina a $1 \%$; depois, com um dedo como guia no canal anal, injecta-se $5 \mathrm{cc}$. da mesma solução de novocaina, atraz do canal anal ao longo do grande eixo do intestino. A agulha que havia penetrado cerca de $5 \mathrm{cms}$. é retirada parcialmente á dirigida um pouco para fóra, para a frente e profundamente na direcção do elevador do anus, onde se injecta $5 \mathrm{cc}$. da solução, a direita e a esquerda. Toda a metade posterior do canal está assim anestesiada. Tanto a incisão como a excisão podem ser feitas sem dôr.

A técnica da excisão é simples; pelo metodo de Gabriel, (fig. VII) retira-se um retalho triangular de pele e mucosa que compreende a fissura. A incisão se inicia imediatamente acima da extremidade superior da fissura, por dois ramos divergentes, em ângulo aberto para a superficie cutânea; é retirado com a fissura um retalho triangular de 
$3 \mathrm{cms}$. de lado aproximadamente. A operação é completada por uma anotomia com secção das fibras mais superficiais do esfíncter externo. Curativo com gaze vaselinada.

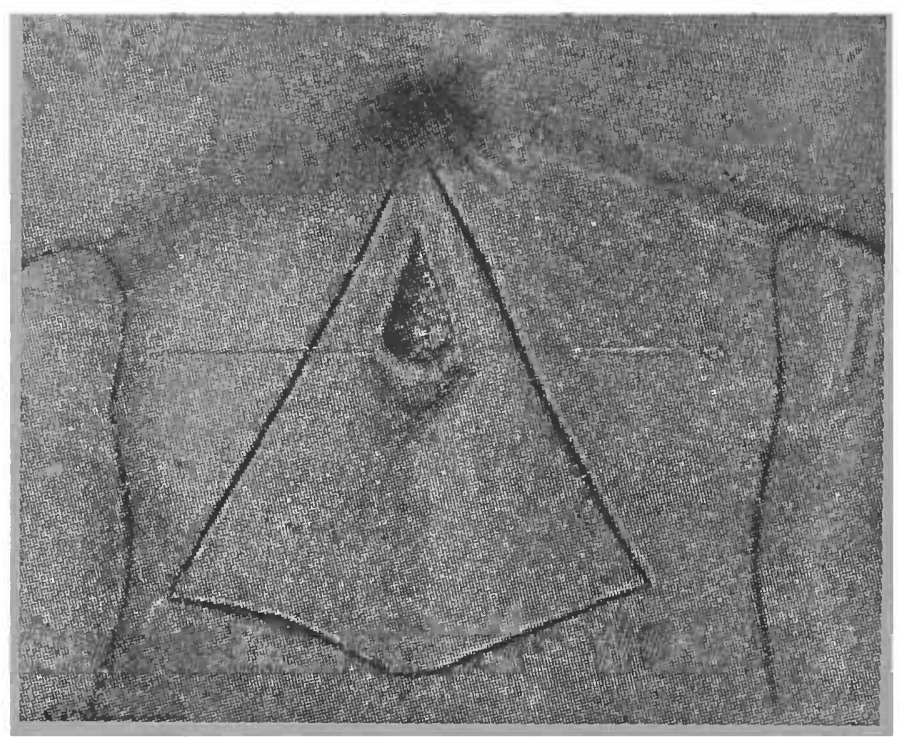

Frg. VII

Gabriel (7).

Buie (fig. VIII), excisa a fissura, incisa as fibras mais superficiaes do esfíncter externo, exçisa um pequeno retalho de pele para anal e sutura as bordas da ferida operatoria. Fecha pois primitivamente. Hirschman, excisa a fissura por incisão em cunha.

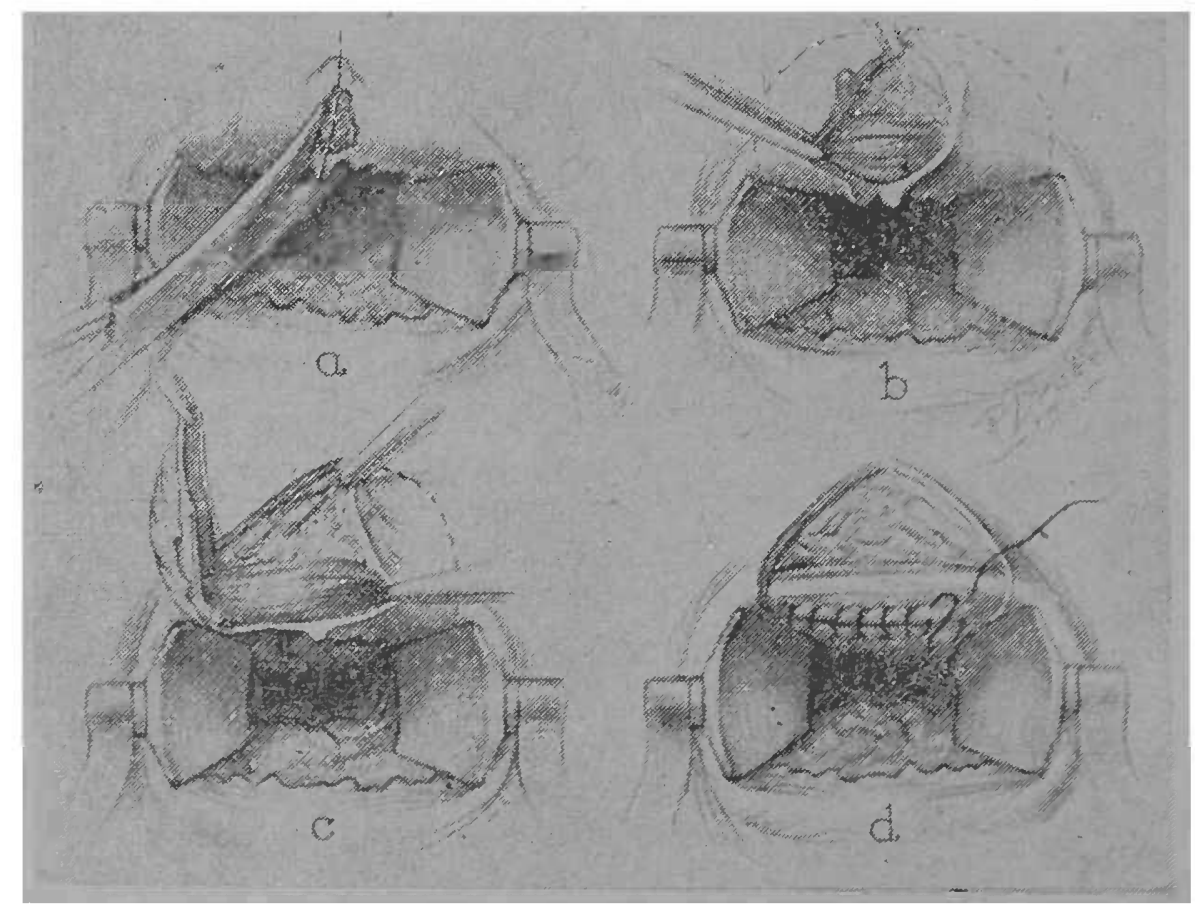

Frg. VIII

Buie (5). 
'Taes são as técnicas de excisão, que tem sua indicação maxima nas fissuras antigas, de base esclerosadas ou rebeldes a outros tratamentos.

O posoperatório nada apresenta de particular. Troca de curativo no dia seguinte e toque com mercurio cromo a $5 \%$, ou violeta de genciana a $1 \%$ quando pelo método de Gabriel, método ambulatório. Seguindo as técnicas de Buie ou de Hirschman ha necessidade de hospitalisação por um ou dois dias para maior repouso. Recomendam os diversos AA. que se permita a movimentação do intestino somente no 3. ${ }^{\circ}$ dia.

\section{BIBLIOGRAFIA}

(1) BACON - Anus, Rectum, Colon Sigmoid. Diag. Treat. Lippincott C. ${ }^{\circ}$, 1938.

(2) Bensaude - Fissure anal. Mond. Med. 47:803-809, Agos. 1 ' 37.

(3) Bensaude, Cain, Lievre - Traitement des fissures anales par les injections locales de quinine 'e d'urèe. Bull. et Mem. d. 1. Societ. Med. Hop. Paris 1930, n..$^{\circ}$.

(4) BLAISDELL - Fissure anal, pathogenesis and implications as to treatment. S. G. O. $65: 672-677$ Nov. ' 37.

(5) BuIE - Practical Proctology. Saunders C. ${ }^{\circ}, 1938$.

(6) Daniels - Anal fissure, anal spasm and anal stenosis. Am. Jour. Digest. Dis. and Nutri.' $3: 775-783$ Dec. '36.

(7) GABRIEI - The principles and practice of retal surgery. H. D. Lewis C. ${ }^{\circ}, 1932$.

(8) HILLER - The anal sphinter and the pathogenesis of anal fissure and fistula. S. G. O. $52: 921-940,1931$.

(9) Hirschman - Handbook of diseases of the rectum. Monby C. ${ }^{\circ}, 1926$.

(10) Levy - Fissure in ano. Am. J. Sur. 36: 244-248 Abril .37.

(11) Lockhart-Mummery - Diseases of the rectum and colon. Bailliere, Tindall C. ${ }^{\circ}, 1934$.

(12) Machline - Le traitement moderne de la fissure anale. Arch. d. mal. de 1.app. diges. e nutr. 26:1050-1057 Nov. '36.

(13) Mrlligan e Morgan - Surgical anatomy of the anal canal with special referense to anoretal fistulas. - Lancet $2: 1150-1156,1213-1217,1934$.

(14) PRUItT - Modern Proctology. Mosby C.o, 1931.

(15) Rankin, Bargen \& Buie - The colon, rectum and anus. Saunders C. 1932.

(16) Seara - Fissuras del ano. Dia Med. 10:468-470 Maio 30 '38.

(17) Senna, Silva G. G. - Pathogenia da fissura anal. Hospital 12:483-486 - Set. '37.

(18) Yeomans - Proctology Appleton C. 1929.

(19) Wriss - Fissure anal, ambulatory treat. Am. J. Surg. 37:88-91 July '38. 